\title{
The effect of particles on creep rate and microstructures of granular ice
}

\author{
Min SONG, ${ }^{1}$ Ian BAKER, ${ }^{2}$ David M. COLE ${ }^{3}$ \\ ${ }^{1}$ State Key Laboratory of Powder Metallurgy, Central South University, Changsha 410083, China \\ ${ }^{2}$ Thayer School of Engineering, Dartmouth College, Hanover, New Hampshire 03755-8000, USA \\ E-mail: ian.baker@dartmouth.edu \\ ${ }^{3}$ US Army Cold Regions Research and Engineering Laboratory, 72 Lyme Road, Hanover, New Hampshire 03755-1290, USA
}

\begin{abstract}
The microstructures of particle-free granular freshwater ice and ice containing 1 wt. $\%$ of $50 \pm 10 \mu \mathrm{m}$ uniformly distributed particles were investigated before and after compressive creep to $\sim 10 \%$ strain with stresses of $1.45 \mathrm{MPa}$ at $-10^{\circ} \mathrm{C}$ and $0.4 \mathrm{MPa}$ at $-5^{\circ} \mathrm{C}$. Creep rates of particle-containing ice were always higher than those of particle-free ice. For an initial stress of $1.45 \mathrm{MPa}$ at $-10^{\circ} \mathrm{C}$, dynamic recrystallization occurred with new grains nucleating and growing along grain boundaries for both sets of specimens, and the ice with particles showed a higher nucleation rate. Under creep with an initial stress of $0.4 \mathrm{MPa}$ at $-5^{\circ} \mathrm{C}$, dynamic recrystallization also occurred by the nucleation and growth of new grains along the grain boundaries for ice containing particles, but recrystallization in the particle-free ice occurred through grain boundary migration.
\end{abstract}

\section{INTRODUCTION}

Microstructural evolution strongly affects the deformation process in ice: both grain size and orientation affect the deformation rates and rate-controlling mechanisms. Decreasing the grain size can change the creep mechanism from dislocation glide to diffusion-based grain boundary sliding (Goldsby and Kohlstedt, 1997). Previous studies (Baker, 1981, 1982) indicated that crystal fabric has important effects on the flow of polycrystalline ice. Jacka and Maccagnan (1984) found a three-fold increase in creep rate as the crystal fabric changed from random to small circle. Cuffey and others (2000a, b) found an enhanced shear strain rate of ice-age ice in South Greenland and suggested that this arose from the development of $c$-axis fabric with a strong shear single-maximum pattern and decrease in grain size, with these two phenomena accounting for roughly $70 \%$ and $30 \%$ of the average enhancement, respectively.

The effect of particles on the creep of polycrystalline ice has been investigated by a number of workers (e.g. Holdsworth and Bull, 1970; Baker and Gerberich, 1979; Shoji and Langway, 1985; Durham and others, 1992). However, the effect of particles on the microstructural evolution in freshwater ice has not been systematically studied. Under high stress, recrystallization may occur through the nucleation and growth of many small grains along the grain boundaries as a consequence of the high strain energy that builds up along grain boundaries. This process will inevitably increase the number of grains. Furthermore, because strain energy can build up around hard inclusions during deformation, soil particles can also stimulate the nucleation of new grains. Under low stress, on the other hand, recrystallization may occur through grain boundary migration since the strain energy along the grain boundaries may not be high enough to nucleate new grains.

The present work was part of a larger research effort to understand how dispersed fine particles affect flow rates in granular freshwater ice, and illustrates how the presence of soil particles influences dynamic recrystallization during compressive creep straining.

\section{EXPERIMENTAL}

Deionized, distilled and degassed water was used to grow thin plates of large-grained ice. These ice plates were then broken up, and a $3-5 \mathrm{~mm}$ sieve fraction was obtained. These grains were used to seed granular freshwater ice specimens prepared by the method of Cole (1979). The final cylindrical specimen dimensions were $127 \mathrm{~mm}$ in length and $50.4 \mathrm{~mm}$ in diameter.

For particle-containing ice, water with silt-sized soil particles (obtained from Hanover, $\mathrm{NH}$, and sieved to $50 \pm 10 \mu \mathrm{m}$ ) was frozen to a thickness of about $5 \mathrm{~mm}$ from bottom to top using a cooling plate. Another layer of ice with particles was then grown on the top of the first layer. This procedure was repeated several times until the thickness of the ice plate was about $30 \mathrm{~mm}$. Growing a multilayer ice plate was necessary to distribute the particles throughout the ice grains. The ice plate was subsequently broken up, and a $3-5 \mathrm{~mm}$ sieve fraction was obtained. These grains were then used to seed granular ice specimens as described above. Both particle-free and particle-containing ice had an average initial grain size of approximately $5 \mathrm{~mm}$. The grain size was determined by measuring the diameter of all the grains in one thin section and taking the average. The maximum error in the average grain size is $<2 \mathrm{~mm}$. Figure 1 shows a thin section and an enlarged view of ice with $1 \mathrm{wt} \%$ $(\sim 0.43$ vol.\%) particles. It can be seen that the particles are uniformly distributed (Fig. 1b).

Constant-load compressive creep tests with an initial stress level of $1.45 \mathrm{MPa}$ at $-10^{\circ} \mathrm{C}$ or $0.4 \mathrm{MPa}$ at $-5^{\circ} \mathrm{C}$ were used to study the effect of particles on the creep behavior. The creep tests were performed using a creep jig, which has been described in detail by Song and others (2005). The creep jig was located in a cold room at a temperature $2{ }^{\circ} \mathrm{C}$ lower than the test temperature. Two insulated boxes were used to isolate the jig from the cold room, and a temperature-regulating system was located between the boxes. This method controlled the temperature in the inner box to $\pm 0.1^{\circ} \mathrm{C}$. To minimize ice sublimation during the long-term creep testing, a rubber cover was put on the surface of the specimens. Eight specimens (four particle-free specimens 

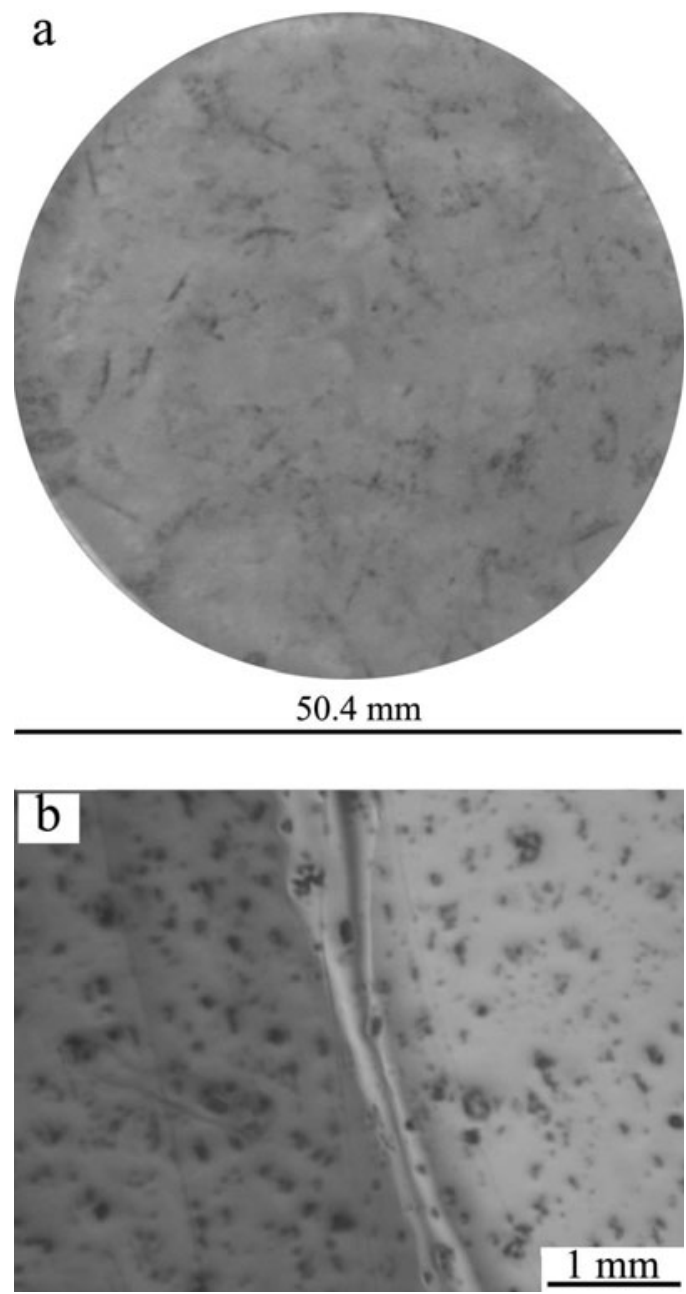

Fig. 1. (a) Photograph of a thin section of an ice specimen with 1 wt.\% particles. (b) Enlarged view of the thin section under polarized light showing the distribution of particles.

and four particle-containing specimens) were used to determine the variability in the creep rate (two specimens for each creep test condition). The maximum variation from the average creep rate was found to be less than $20 \%$. After the creep strain reached $\sim 10 \%$, the stress had decreased to $\sim 1.3$ or $\sim 0.36 \mathrm{MPa}$, respectively, about $10 \%$ lower than the initial stress, due to the increase in the specimen's crosssectional area. A load cell mounted in line with the specimens monitored the axial load, and two displacement transducers mounted on circumferential rings (located at one-third and two-thirds along the length of the specimens) provided the deformation measurements.

The specimens were thin-sectioned after creep straining to $\sim 10 \%$ and compared with thin sections of unstrained material in order to study the effects of particles on the microstructures during creep. Microstructural analysis was performed using optical microscopy with polarized light.

\section{RESULTS}

\subsection{Creep}

Figure 2 shows the relationship between strain rate and strain for both the particle-free and the particle-containing ice under creep with initial stress levels of $1.45 \mathrm{MPa}$ at $-10^{\circ} \mathrm{C}$ and $0.4 \mathrm{MPa}$ at $-5^{\circ} \mathrm{C}$. Note that for both circumstances (high
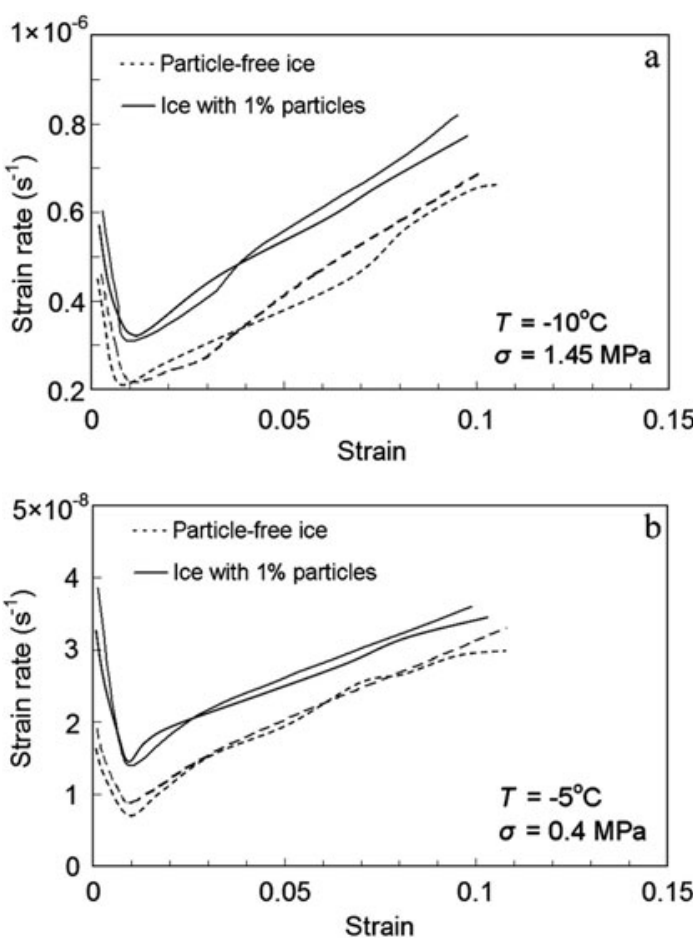

Fig. 2. Relationship between strain rate and strain of particle-free ice and particle-containing ice ( $1 \mathrm{wt} . \%$ ). (a) Initial stress of $1.45 \mathrm{MPa}$ at $-10^{\circ} \mathrm{C}$. (b) Initial stress of $0.4 \mathrm{MPa}$ at $-5^{\circ} \mathrm{C}$. Note that each condition includes two curves from two specimens.

creep stress and low creep stress), the creep rate of the particle-containing ice was always higher than that of the particle-free specimens, even at strains that are too low for appreciable recrystallization to occur. This agrees well with a previous study (Song and others, 2004), in which particles are distributed only along the grain boundaries and also show increased creep rates, compared to those of particlefree ice. That analysis indicated that the higher creep rates of ice with particles was due to an increased dislocation density caused by the particles. Since under these conditions $\left(1.45 \mathrm{MPa}\right.$ at $-10^{\circ} \mathrm{C}$ and $0.4 \mathrm{MPa}$ at $\left.-5^{\circ} \mathrm{C}\right)$ the main creep mechanism is dislocation glide on the basal plane (Duval and others, 1983), an increase in dislocation density will inevitably increase the creep rate. The curves in Figure 2 show typical creep behavior: the creep rate initially decreases (primary creep) to a minimum value and then increases (tertiary creep). It can be seen that the strain at the minimum creep rate is about $1 \%$ for both particle-free ice and particle-containing ice, in accordance with previous studies (Mellor and Cole, 1983; Jacka, 1984). Jones and Chew (1981) examined the effect of the ratio of crosssectional diameter of the specimen to the grain size for slow strain-rate compression tests on ice. They found that the strength was clearly independent of this ratio for values greater than 11-12 and was clearly dependent on the ratio for values of $\sim 8$. More generally, a ratio of specimen diameter to grain size of 10:1 is considered sufficient for the specimen to act as a true polycrystal. In the present work, the ratio of specimen diameter to grain size was 10:1.

\subsection{Microstructures}

Figure 3 shows thin sections of the particle-free and particlecontaining ice between crossed polarizers before and after creep to $\sim 10 \%$ strain. Figure 4 shows higher-magnification 


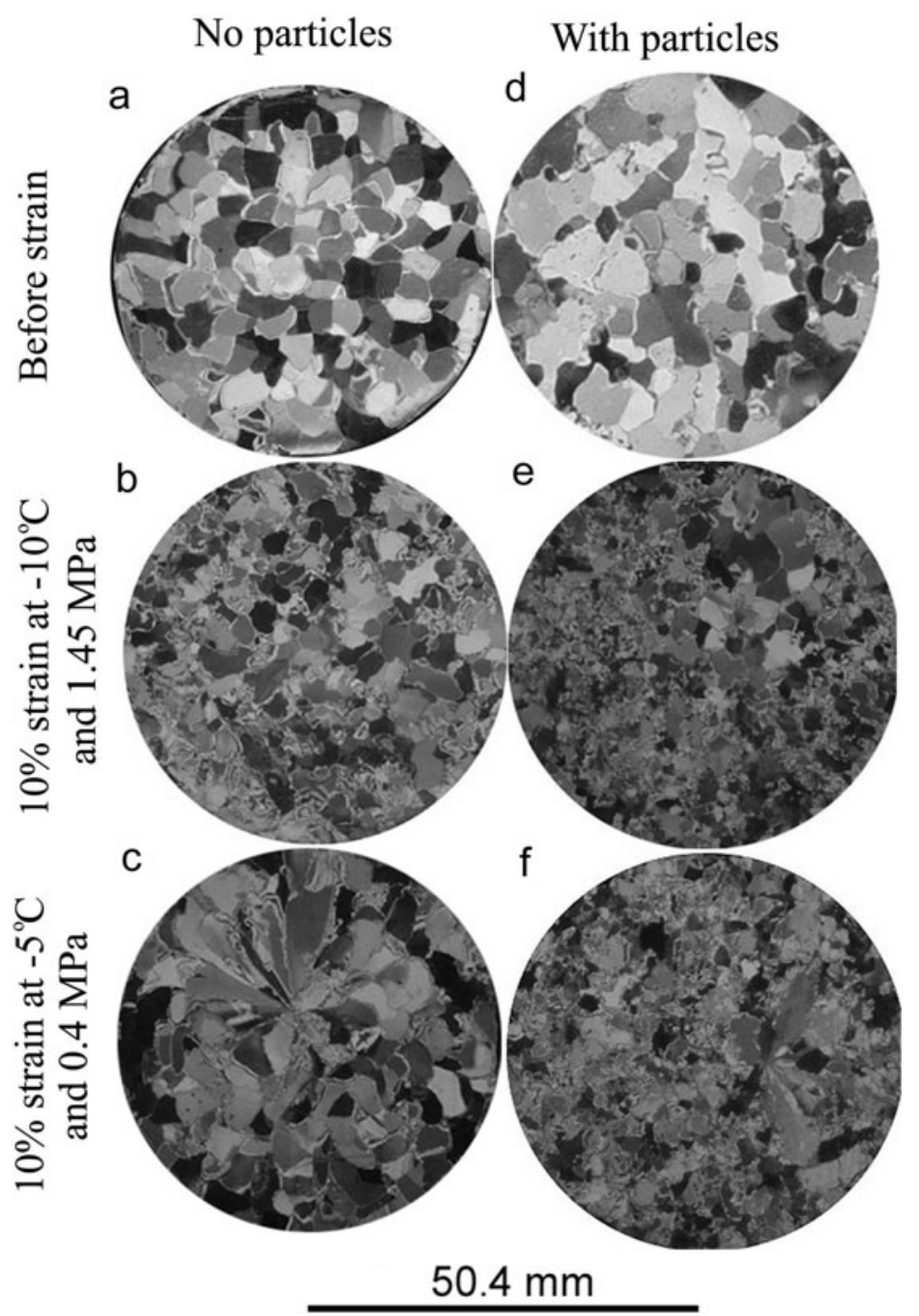

Fig. 3. Thin sections of both particle-free ice $(\mathrm{a}-\mathrm{c})$ and particle-containing ice $(1 \mathrm{wt} . \%)(\mathrm{d}-\mathrm{f})$ between crossed polarizers before and after strain to $\sim 10 \%$. (a, d) No strain; (b, e) initial stress of $1.45 \mathrm{MPa}$ at $-10^{\circ} \mathrm{C}$; and (c, f) initial stress of $0.4 \mathrm{MPa}$ at $-5^{\circ} \mathrm{C}$.

images, where it is evident that dynamic recrystallization has occurred throughout the specimen after creep to $10 \%$ strain at $1.45 \mathrm{MPa}$ and $-10^{\circ} \mathrm{C}$. New grains replace the initial microstructure, resulting in a decrease in the average grain size after $10 \%$ strain. It should be noted that particlecontaining ice has a much higher recrystallization ratio $(>80 \%)$ and smaller grain size after creep, compared to particle-free ice $(<50 \%)$. After creep to $\sim 10 \%$ strain at $0.4 \mathrm{MPa}$ and $-5^{\circ} \mathrm{C}$, the whole microstructure of particlecontaining ice was largely recrystallized, and almost all the old grains were replaced by the new, small recrystallized grains. However, no small grains appeared in the particlefree ice since the recrystallization is through grain boundary migration. Table 1 shows the relationship between average grain size and strain level for particle-free and particlecontaining ice before and after creep to $\sim 10 \%$ strain (two values for each test condition). It can be seen that the ice with particles shows a much larger grain-size reduction compared to the particle-free ice.

\section{DISCUSSION}

The laboratory results clearly show that the creep rate of particle-containing ice is higher than that of particle-free ice under either high or low creep stress. It is well known that dislocation glide along the basal plane is the main deformation mechanism at stresses higher than $0.2 \mathrm{MPa}$ and temperatures from $-0.05^{\circ} \mathrm{C}$ to $-50^{\circ} \mathrm{C}$ (Budd and Jacka, 1989). Although fabric development and an increase in grain boundary sliding (due to grain refinement) may help increase the creep rate in tertiary creep, they are not the main reasons for the higher creep rates in the ice with particles. This is especially evident in the early stages of creep, when dynamic recrystallization has only just begun, but creep rates are nonetheless higher when particles are present. Generally, the creep rate is affected by both the dislocation density and the dislocation glide velocity. Under the same temperature and stress conditions, dislocation glide should have the same (or similar) average velocity for a randomly oriented polycrystal, even if coarsely spaced particles are present. Thus, the creep rate is controlled by the dislocation density. It is evident that the particles cause an increase in the dislocation density relative to particle-free ice, and that this difference persists as straining proceeds, and produces higher creep rates through all stages of creep deformation. Since the particles are distributed uniformly throughout the microstructure, three possible mechanisms might help generate a higher dislocation density, compared with particle-free ice. First, the particles inside the grain interiors can develop stress concentrations during deformation, and 


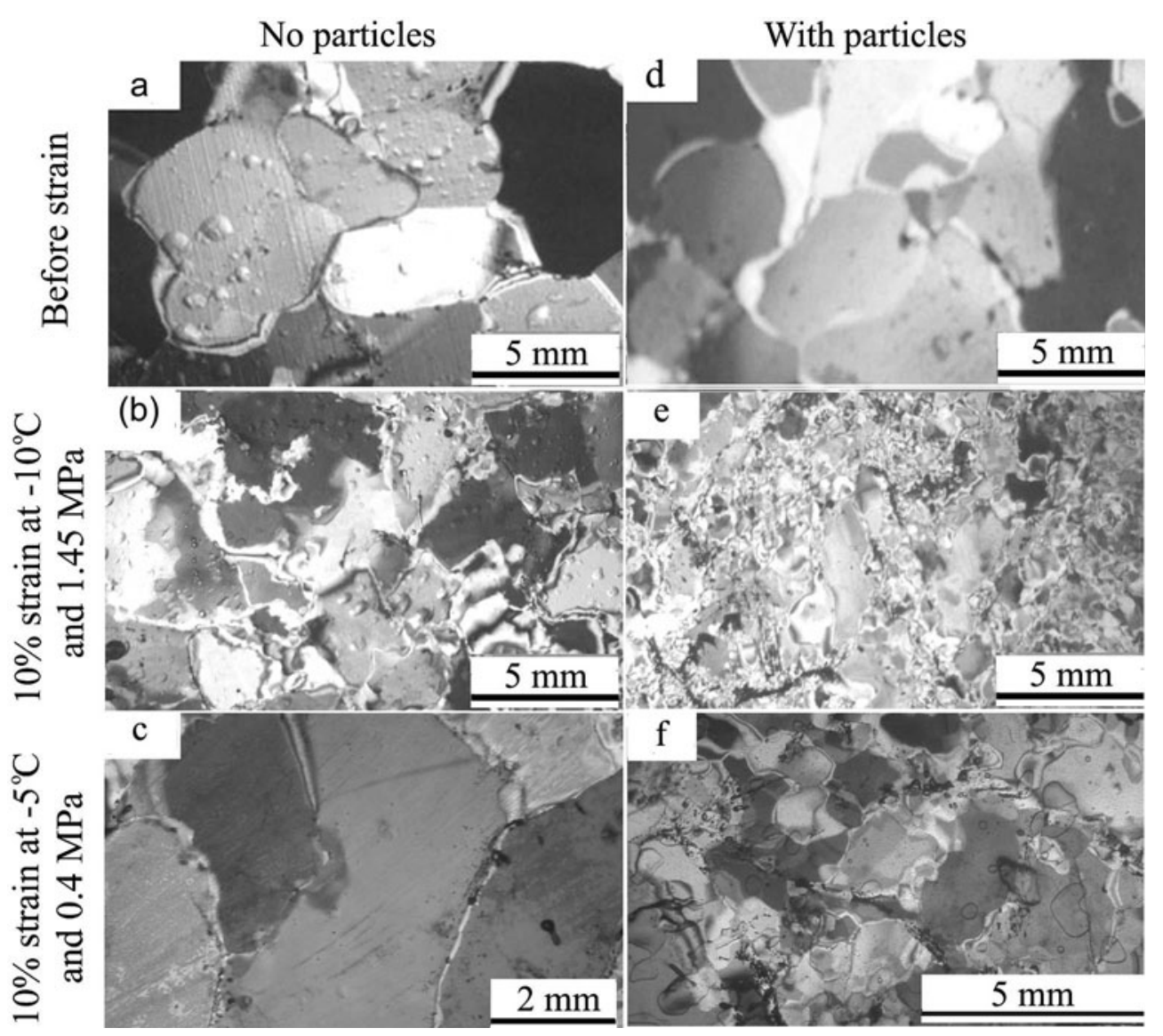

Fig. 4. Enlarged microstructural views of the respective thin sections shown in Figure 3.

thus increase the dislocation nucleation rates sufficiently to enhance creep rates. Second, the particles along the grain boundaries can inhibit grain boundary sliding, leading to intergranular stress concentrations, and thus increasing the dislocation density. Third, differences in the thermal expansion coefficients of ice and soil particles can lead to stress concentrations and produce dislocations.

Under the higher creep stress of $1.45 \mathrm{MPa}$, dynamic recrystallization is through nucleation and growth of new grains for both particle-free ice and particle-containing ice. When particles are present along the grain boundaries (Song and others, 2004), they inhibit grain boundary sliding so that even at the $0.4 \mathrm{MPa}$ stress level, the resulting build-up of strain energy makes the grain boundaries favorable sites for the nucleation of new grains. This has the effect of increasing the nucleation rate for new grains and leads to a greater reduction in grain size with increasing strain compared to the particle-free ice. This phenomenon is in accordance with a previous study (Song and others, 2004), which focused on the effect of particles that are located only along the grain boundaries. It should be noted that the particles inside the grains can also act as nucleation sites for new grains due to the strain energy built up around them (Ahmad and others, 1992).

In contrast, for particle-free ice deformed at the $0.4 \mathrm{MPa}$ stress level, dynamic recrystallization involved grain boundary migration instead of the nucleation of new grains. In this case, the build-up of strain energy is sufficient to drive grain boundary migration, but is insufficient to drive the nucleation of new grains. The microstructural consequence of recrystallization by grain boundary migration is that the grain size is not reduced.

According to the above discussion, the particles increase both dislocation multiplication and dynamic recrystallization (nucleation of new grains). Both processes increase the creep rate. Dislocation multiplication increases the creep rate by increasing the dislocation density, while dynamic recrystallization increases the creep rate by decreasing the grain size and changing the grain orientations of the specimens. However, dynamic recrystallization generally decreases the dislocation density. From Figures 2 and 4 we know that the ice with particles has both a higher creep rate and a higher grain nucleation rate throughout the whole deformation process than the particle-free ice. Therefore, it is evident that the decrease in dislocation density due to dynamic recrystallization is low compared to the increase in dislocation density associated with the presence of the particles. An earlier study (Hooke and others, 1972) suggested that for ice containing particles the creep stress exponent, $n$, may be less than 2. However, our previous study (Song and others, 2006) showed that from 0.4 MPa to 1.4 MPa and from $-20^{\circ} \mathrm{C}$ to $-2^{\circ} \mathrm{C}, n=3$ for both particle-free ice and ice containing particles, with higher creep rates for particlecontaining ice.

\section{CONCLUSION}

The effect of particles on the creep rate and microstructures in granular freshwater ice has been investigated and the following conclusions are drawn: 
Table 1. The relationship between average grain size and strain for both particle-free ice and particle-containing ice (1 wt.\%). Two tests were performed for each condition

\begin{tabular}{|c|c|c|c|c|}
\hline \multirow[t]{3}{*}{ Strain } & \multicolumn{4}{|c|}{ Average grain size } \\
\hline & \multicolumn{2}{|c|}{ Particle-free ice } & \multicolumn{2}{|c|}{ Particle-containing ice (1 wt.\%) } \\
\hline & $-10^{\circ} \mathrm{C}, 1.45 \mathrm{MPa}$ & $-5^{\circ} \mathrm{C}, 0.4 \mathrm{MPa}$ & $-10^{\circ} \mathrm{C}, 1.45 \mathrm{MPa}$ & $-5^{\circ} \mathrm{C}, 0.4 \mathrm{MPa}$ \\
\hline$\%$ & $\mathrm{~mm}$ & $\mathrm{~mm}$ & $\mathrm{~mm}$ & $\mathrm{~mm}$ \\
\hline 0 & $\sim 5, \sim 5$ & $\sim 5, \sim 5$ & $\sim 5, \sim 5$ & $\sim 5, \sim 5$ \\
\hline$\sim 10$ & $\sim 2.2, \sim 2.0$ & $\sim 5.6, \sim 4.9$ & $\sim 0.3, \sim 0.2$ & $\sim 0.8, \sim 1.0$ \\
\hline
\end{tabular}

1. Particle-containing ice $(1 \mathrm{wt} . \%)$ shows a higher creep rate compared to particle-free ice.

2. Under an initial creep stress of $1.45 \mathrm{MPa}$ at $-10^{\circ} \mathrm{C}$, dynamic recrystallization occurs through the nucleation of new grains along grain boundaries for both particlefree and particle-containing ice.

3. Under an initial creep stress of $0.4 \mathrm{MPa}$ at $-5^{\circ} \mathrm{C}$, dynamic recrystallization occurs through the nucleation of new grains along grain boundaries for particle-containing ice but through grain boundary migration for particle-free ice.

4. Particles inhibit grain boundary sliding and enhance dynamic recrystallization through the nucleation of new grains, thus dramatically increasing the nucleation rate and decreasing the average grain size.

\section{ACKNOWLEDGEMENTS}

This research was supported by the US National Science Foundation (NSF) Office of Polar Programs, Arctic Natural Sciences Program (OPP 011737). We thank G. Durell for valuable assistance in developing the creep loading equipment.

\section{REFERENCES}

Ahmad, S., C. Shearwood and R.W. Whitworth. 1992. Dislocation multiplication mechanisms in ice. In Maeno, N. and T. Hondoh, eds. Physics and chemistry of ice. Sapporo, Hokkaido University Press, 492-496.

Baker, R.W. 1981. Textural and crystal-fabric anisotropies and the flow of ice masses. Science, 211(4486), 1043-1044.

Baker, R.W. 1982. A flow equation for anisotropic ice. Cold Reg. Sci. Technol., 6(2), 141-148.

Baker, R.W. and W.W. Gerberich. 1979. The effect of crystal size and dispersed-solid inclusions on the activation energy for creep of ice. J. Glaciol., 24(90), 179-194.

Budd, W.F. and T.H. Jacka. 1989. A review of ice rheology for ice sheet modelling. Cold Reg. Sci. Technol., 16(2), 107-144.

Cole, D.M. 1979. Preparation of polycrystalline ice specimens for laboratory experiments. Cold Reg. Sci. Technol., 1(2), 153-159.
Cuffey, K.M., H. Conway, A. Gades, B. Hallet, C.F. Raymond and S. Whitlow. 2000a. Deformation properties of subfreezing glacier ice: role of crystal size, chemical impurities, and rock particles inferred from in situ measurements. J. Geophys. Res., 105(B12), 27,895-27,915.

Cuffey, K.M., T. Thorsteinsson and E.D. Waddington. 2000b. A renewed argument for crystal size control of ice sheet strain rates. J. Geophys. Res., 105(B12), 27,889-27,894.

Durham, W.B., S.H. Kirby and L.A. Stern. 1992. Effects of dispersed particulates on the rheology of water ice at planetary conditions. J. Geophys. Res., 97(E12), 20,883-20,897.

Duval, P., M.F. Ashby and I. Anderman. 1983. Rate-controlling processes in the creep of polycrystalline ice. J. Phys. Chem., 87(21), 4066-4074.

Goldsby, D.L. and D.L. Kohlstedt. 1997. Grain boundary sliding in fine-grained ice I. Scripta Mater., 37(9), 1399-1406.

Holdsworth, G. and C. Bull. 1970. The flow of cold ice: investigations on Meserve Glacier, Antarctic. IASH Publ. 86 (Symposium at Hanover 1968 - Antarctic Glaciological Exploration (ISAGE)), 204-216.

Hooke, R.LeB., B.B. Dahlin and M.T. Kauper. 1972. Creep of ice containing dispersed fine sand. J. Glaciol., 11(63), 327-336.

Jacka, T.H. 1984. The time and strain required for development of minimum strain rates in ice. Cold Reg. Sci. Technol., 8(3), 261-268.

Jacka, T.H. and M. Maccagnan. 1984. Ice crystallographic and strain rate changes with strain in compression and extension. Cold Reg. Sci. Technol., 8(3), 269-286.

Jones, S.J. and H.A.M. Chew. 1981. Correspondence. On the grain-size dependence of secondary creep. J. Glaciol., 27(97), 517-518.

Mellor, M. and D.M. Cole. 1983. Stress/strain/time relations for ice under uniaxial compression. Cold Reg. Sci. Technol., 6(3), 207-230.

Shoji, H. and C.C. Langway, Jr. 1985. Comparison of mechanical test on the Dye-3, Greenland ice core and artificial laboratory ice. Ann. Glaciol., 6, 306-308.

Song, M., D.M. Cole and I. Baker. 2004. Initial experiments on the effects of particles at grain boundaries on the anelasticity and creep behavior of granular ice. Ann. Glaciol., 39, 397-401.

Song, M., D.M. Cole and I. Baker. 2005. Creep of granular ice with and without dispersed particles. J. Glaciol., 51(173), 210-218.

Song, M., D.M. Cole and I. Baker. 2006. An investigation of the effects of particles on creep of polycrystalline ice. Scripta Mater., 55(1), 91-94. 